\title{
Iodine-125 irradiation inhibits invasion of gastric cancer cells by reactivating microRNA-181c expression
}

\author{
YONG YANG ${ }^{1-3}$, ZHEN-HUAN MA ${ }^{1-3}$, XIAO-GANG LI ${ }^{1,4}$, WAN-FU ZHANG ${ }^{1,4}$, JIA WAN ${ }^{1-3}$, \\ LING-JUAN DU ${ }^{1-3}$, GUO-JIAN LI ${ }^{1-3}$, GUO-KAI YANG ${ }^{1-3}$ and PING LU ${ }^{1-3}$ \\ ${ }^{1}$ Department of General Surgery, The Second People's Hospital of Yunnan; ${ }^{2}$ Department of Vascular Surgery, \\ Fourth Affiliated Hospital to Kunming Medical University; ${ }^{3}$ Vascular Surgery Centre in Yunnan; ${ }^{4}$ Abdominal Surgery Centre, \\ The Health and Family Planning Commission of Yunnan Kunming, Kunming, Yunnan 650021, P.R. China
}

Received February 26, 2015; Accepted June 7, 2016

DOI: $10.3892 / \mathrm{ol} .2016 .5033$

\begin{abstract}
Iodine-125 ( $\left.{ }^{125} \mathrm{I}\right)$ seed implantation has been widely used for the treatment of unresectable advanced tumors. However, the molecular mechanisms underlying the tumor-suppressive effects of ${ }^{125} \mathrm{I}$ irradiation have not been fully elucidated. The present study demonstrated that ${ }^{125}$ I irradiation suppresses cell viability and inhibits cell invasiveness of gastric cancer KATO-III and MKN45 cells. Further mechanistic analysis suggested the involvement of microRNA (miR)-181c in the inhibitory effects induced by ${ }^{125} \mathrm{I}$ irradiation. Methylated DNA immunoprecipitation coupled with quantitative-polymerase chain reaction demonstrated that treatment with ${ }^{125} \mathrm{I}$ irradiation, at the dose of 4 Gy, induced promoter demethylation of the miR-181c gene in KATO-III and MKN45 cells. Following irradiation, the expression of miR-181c was significantly increased, which may be attributed to the demethylation caused by ${ }^{125} \mathrm{I}$ irradiation. In addition, upregulation of miR-181c by administration of miR-181c mimics decreased cell invasion, suggesting the role of miR-181c as a tumor suppressor. More importantly, the tumor-suppressive effects of ${ }^{125} \mathrm{I}$ irradiation were significantly compromised by the introduction of miR-181c inhibitors. Overall, these results reveal that ${ }^{125} \mathrm{I}$ irradiation inhibits invasiveness of gastric cancer cells by reactivating miR-181c at the epigenetic level, thereby providing important molecular evidence for the anticancer effects of ${ }^{125}$ I irradiation.
\end{abstract}

\section{Introduction}

Gastric cancer is one of the most common human malignancies, globally accounting for $\sim 1$ million novel cases and $>700,000$

Correspondence to: Dr Zhen-Huan Ma, Department of General Surgery, The Second People's Hospital of Yunnan, 176 Youth Road, Kunming, Yunnan 650021, P.R. China

E-mail: ma_zhenhuan@qq.com

Key words: ${ }^{125}$ I irradiation, gastric cancer, invasion, microRNA, miRNA, DNA methylation cancer-associated mortalities annually (1). Surgical resection remains the primary treatment for gastric cancer; however, $\sim 60 \%$ of patients have locally advanced and metastatic disease at the time of surgery, leading to a relatively low therapeutic efficacy (2). Therefore, nonsurgical methods have attracted increasing attention (3).

Iodine-125 $\left({ }^{125} \mathrm{I}\right)$ seeds have a long half-life and low energy with excellent stability, which has resulted in their extensive clinical use (4). Brachytherapy with low-dose ${ }^{125}$ I seeds has been demonstrated to be an effective salvage therapy for gastric cancer and other malignant carcinomas (5-10). Although ${ }^{125}$ I seed implantation has been successfully utilized in clinics, its radiobiological effect and underlying molecular mechanisms have not been fully elucidated. Recent evidence has indicated that altered DNA methylation patterns have a critical role in tumor inhibition resulting from ${ }^{125}$ I irradiation (3). In addition, consecutive low-energy ${ }^{125}$ I irradiation significantly inhibits the expression of DNA methyltransferases (DNMTs) in cancer cells (11). Following a decrease in DNMT expression, the irradiation-induced DNA demethylation contributes to tumor inhibition by reactivating tumor suppressor genes (11).

MicroRNAs (miRs) are small non-coding RNAs that function as endogenous silencers of numerous target genes. Downregulation of miRs is a common characteristic observed in various types of cancer, suggesting that these molecules may act as a novel class of tumor suppressors (12-18). Previous studies have revealed that a growing number of tumor suppressor miRs are inactivated by promoter hypermethylation in cancers (19-27). One of these miRs, miR-181c, is silenced in gastric cancer by promoter hypermethylation. Furthermore, when miR-181c expression is upregulated, it has been demonstrated to induce growth inhibition of gastric cancer cells, suggesting its role as a potential tumor suppressor in gastric cancer (20). Based on these studies, the present study hypothesized that tumor suppressor miRs, which are epigenetically silenced in cancer, may be activated by irradiation-inducing DNA demethylation and contribute to the anticancer effects of ${ }^{125}$ I irradiation. The aim of the present study was to evaluate whether miR-181c is regulated by ${ }^{125} \mathrm{I}$ irradiation and is involved in irradiation-triggering tumor inhibition in gastric cancer cells. 


\section{Materials and methods}

Cell culture. Human gastric cancer KATO-III and MKN45 cell lines were purchased from the Shanghai Institute of Cytobiology of the Chinese Academy of Sciences (Shanghai, China). The cells were cultured in RPMI-1640 (Thermo Fisher Scientific, Inc., Waltham, MA, USA) supplemented with $10 \%$ fetal bovine serum (FBS; Gibco ${ }^{\circledR}$; Thermo Fisher Scientific, Inc.), $100 \mathrm{U} / \mathrm{ml}$ penicillin and $100 \mu \mathrm{g} / \mathrm{ml}$ streptomycin. All cell lines were maintained at $37^{\circ} \mathrm{C}$ in a humidified incubator containing $5 \% \mathrm{CO}_{2}$.

${ }^{125}$ I irradiation treatment of gastric cancer cells. In-house ${ }^{125} \mathrm{I}$ seeds were obtained from Beijing Atom and High Technique Industries, Inc. (Beijing, China). An in vitro irradiation model was constructed as previously described (28). The absorbed dose was measured and verified as follows: 44, 92, 144 and $204 \mathrm{~h}$ were required for doses of 2, 4, 6 and $8 \mathrm{~Gy}$, respectively.

MTT assay. Cell viability was determined by measuring the ability of the cells to transform thiazolyl blue tetrazolium bromide (MTT) to a purple formazan dye as previously described $(28,29)$. Briefly, cells were irradiated and $20 \mu 1$ MTT solution was added to the cells in each well of a 96-well plate and incubated for $5 \mathrm{~h}$. The medium was replaced with dimethyl sulfoxide to dissolve the purple formazan. The color intensity of the formazan solution, which is positively associated with cell viability, was measured with a microplate spectrophotometer (VersaMax ${ }^{\mathrm{TM}}$; Molecular Devices, LLC, Sunnyvale, CA, USA) at $570 \mathrm{~nm}$.

Transwell invasion assay. Invasiveness of gastric cancer cells were measured using a modified Boyden chamber (BD Bioscience, Franklin Lakes, NJ, USA). Briefly, the gastric cancer cell suspensions were obtained $92 \mathrm{~h}$ following irradiation at a total dose of $4 \mathrm{~Gy}$. In total, $10^{4}$ cells were plated in $200 \mu \mathrm{l}$ RPMI-1640 containing 10\% FBS in the upper chambers of the Boyden chamber. The lower chambers were filled with $500 \mu 1$ RPMI-1640 containing 10\% FBS. Subsequently, cells were incubated for $48 \mathrm{~h}$ at $37^{\circ} \mathrm{C}$, and the membrane was stained with crystal violet and viewed under a microscope to calculate the average number of invasive cells.

Western blotting. Total protein from gastric cancer cells was extracted using RIPA lysis buffer (Cloud-Seq, Inc., Shanghai, China) and quantified using a BCA assay (Pierce ${ }^{\mathrm{TM}}$; Thermo Fisher Scientific, Inc.). Protein extracts were separated using sodium dodecyl sulfate-polyacrylamide gel electrophoresis and transferred onto a nitrocellulose membrane using RapidBlot Transfer Buffer (Cloud-Seq, Inc.). The membranes were hybridized with the following primary antibodies overnight at $4^{\circ} \mathrm{C}$ : Mouse monoclonal anti-DNA (cytosine-5)-methyltransferase 1 (DNMT1; catalog no., sc-271729; dilution, 1:200); and mouse monoclonal anti-glyceraldehyde 3-phosphate dehydrogenase (GAPDH; catalog no., sc-365062; dilution, 1:200) (Santa Cruz Biotechnology,Inc., Dallas, TX,USA). Subsequently, membranes were probed with horseradish peroxidase-conjugated goat anti-mouse secondary antibody (catalog no., 115-035-003; dilution, 1:10,000; Jackson ImmunoReserach, West Grove, PA, USA) for $1 \mathrm{~h}$ at room temperature, and the immunoreactive signals were detected using a SuperSen Enhanced Chemiluminescence kit (Cloud-Seq, Inc.). The DNMT1 protein expression levels were normalized to GAPDH. The signal intensities on western blots were semi-quantified using ImageJ version 1.43 software (National Institutes of Health, Bethesda, MA, USA).

Methylated DNA immunoprecipitation (MeDIP)-quantitative polymerase chain reaction $(q P C R)$ assay. The MeDIP assay coupled with qPCR was used to quantitatively evaluate the methylation status of miR-181c in the cells treated without (control) or with $4 \mathrm{~Gy}$ of ${ }^{125} \mathrm{I}$ irradiation. MeDIP was performed as described previously (3). Briefly, genomic DNA was extracted from cells using DNeasy Blood and Tissue kit (Qiagen, Inc., Hilden, Germany), according to the manufacturer's protocol, and sonicated to produce random fragments $\sim 200-600 \mathrm{bp}$ in size. Following denaturation at $95^{\circ} \mathrm{C}$ for $10 \mathrm{~min}$, immunoprecipitation was performed using a mouse monoclonal anti-5-methylcytidine antibody (catalog no., 39649; dilution 1:10; incubation, $2 \mathrm{~h}$ at $4^{\circ} \mathrm{C}$; Active Motif, Carlsbad, CA, USA). Immunoprecipitated complexes were collected with Dynabeads ${ }^{\circledR}$ Protein A (Thermo Fisher Scientific, Inc.), and the methylated DNA fragments were purified by phenol-chloroform extraction and isopropanol precipitation. Subsequently, methylated DNA fragments and input DNA were analyzed by qPCR using an ABI 7900 Real-Time PCR System (Applied Biosystems $^{\mathrm{TM}}$; Thermo Fisher Scientific, Inc.) and Rapid SYBR Green PCR Master Mix from Cloud-Seq, Inc. The following cycling conditions were used: $95^{\circ} \mathrm{C}$ for $1 \mathrm{~min}$, followed by 40 cycles of $95^{\circ} \mathrm{C}$ for $15 \mathrm{sec}$, then $60^{\circ} \mathrm{C}$ for $1 \mathrm{~min}$, concluding with melt curve analysis. The relative changes in the extent of gene methylation were determined by measuring the amount of detected genes in methylated DNA fragments following normalization to the input DNA (30). The primer sequences targeting the promoter of miR-181c were synthesized by Sangon Biotech Co., Ltd. (Shanghai, China) as follows: Forward, 5'-GAGGGATGAGGA AATGGA-3' and reverse, 5'-TCACAACAGCGTGAGTGG-3'. The experiment was performed in triplicate.

Transfection of cells with miR-181c mimic and inhibitor. miR-181c was repressed or overexpressed by transfection of cells with miR inhibitor or miR mimics using Lipofectamine $^{\circledR} 2000$ (Invitrogen $^{\mathrm{TM}}$; Thermo Fisher Scientific, Inc.), according to the manufacturer's protocol. miR-181c mimic and scrambled control miR sequences were designed and synthesized by GenePharama Co., Ltd. (Shanghai, China) as follows: miR-181c mimic, sense 5'-AACAUUCAACCU GUCGGUGAGUUA-3' and antisense 5'-ACUCACCGACAG GUUGAAUGUUUU-3'; miR-181c inhibitor, sense 5'-TAA CUCACCGACAGGUUGAAUGUU-3'; scrambled negative control, sense 5'-UUGUACUACACAAAAGUACUG-3'. All of the oligonucleotides were transfected at a final concentration of $100 \mathrm{nM}$. Following transfection, the expression of miR-181c was confirmed by qPCR.

Reverse transcription- $q P C R$. In total, $\sim 5 \times 10^{6}$ cells were treated without (control) or with 4 Gy of ${ }^{125}$ I irradiation. Total RNA was extracted from cells using ExRNA Reagent (Cloud-Seq, Inc.), according to manufacturer's protocol. Total RNA from each sample was quantified using NanoDrop ND-1000 (NanoDrop; Thermo Fisher Scientific, Inc., Wilmington, DE, USA), and RNA integrity was assessed by standard denaturing 


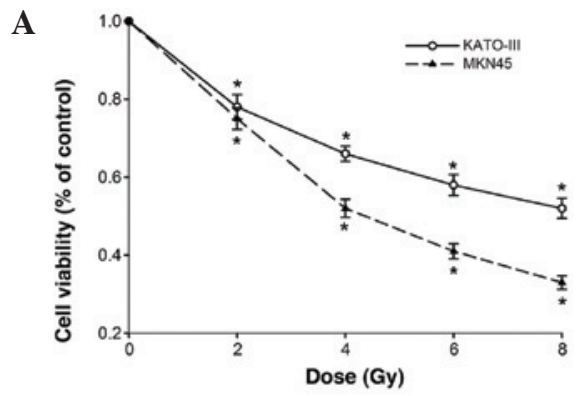

B

C
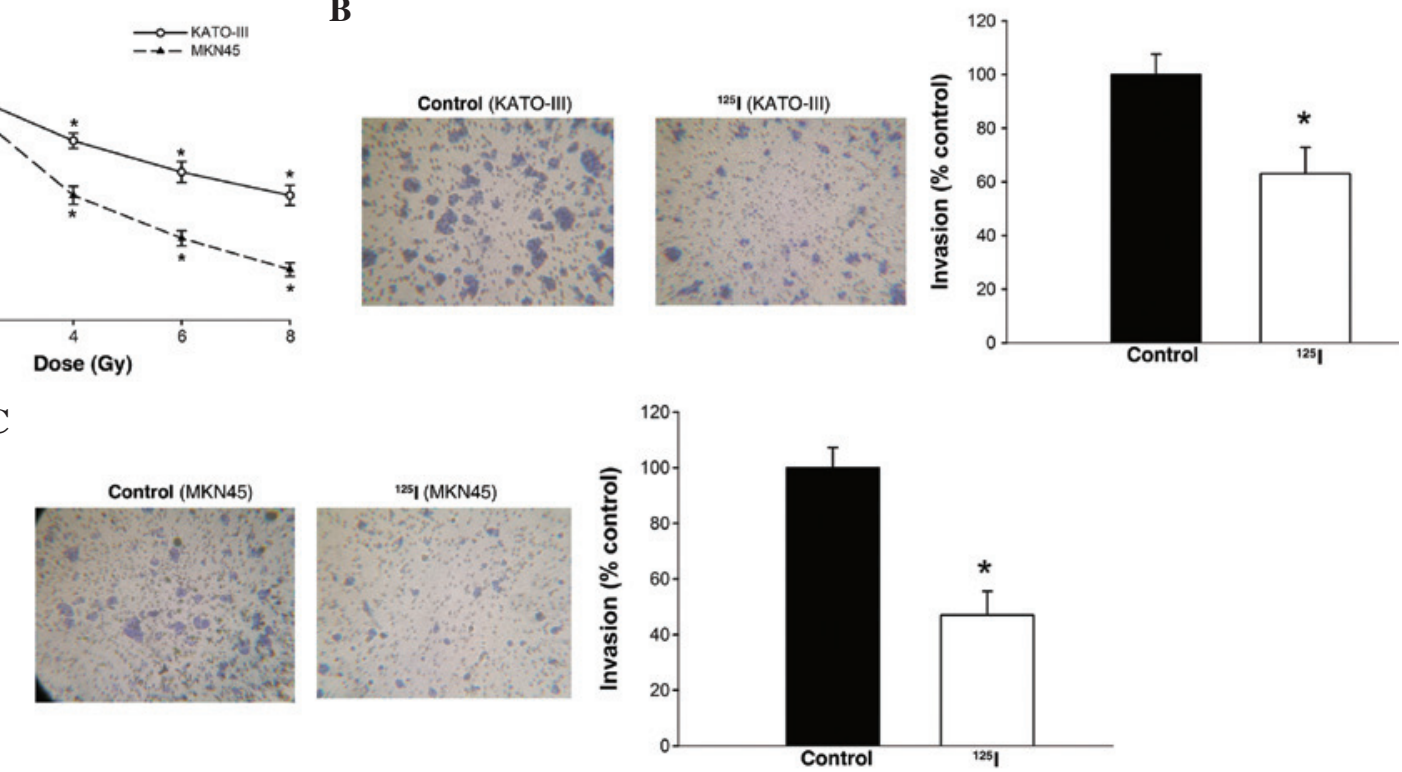

Figure 1. ${ }^{125}$ I seed irradiation inhibits viability and invasiveness of human gastric cancer KATO-III and MKN45 cells. (A) Cell viability of KATO-III and MKN45 cells treated at various doses of ${ }^{125}$ I irradiation was examined by MTT assay. (B and C) Invasive abilities of (B) KATO-III and (C) MKN4 cells treated with 0 and $4 \mathrm{~Gy}{ }^{125} \mathrm{I}$ irradiation were evaluated by Transwell analysis. The number of cells was counted in 10 fields per chamber to calculate the average number of invasive cells. Data are presented as the mean \pm standard error of the mean $(n=3) .{ }^{*} \mathrm{P}<0.05$ vs. 0 Gy treated cells. ${ }^{125} \mathrm{I}$, iodine-125.

agarose gel electrophoresis. miRs and mRNAs were processed into cDNA using a FlashScript Reverse Transcription kit (Cloud-Seq, Inc.) with a miR-181c-specific stem loop primer and oligo dT (18) primer. qPCR was performed with Rapid SYBR PCR Master Mix (Cloud-Seq, Inc.) on an ABI 7900 Real-Time PCR System. Primers were synthesized by Sangon Biotech Co., Ltd. as follows: U6, forward 5'-CTCGCTTCG GCAGCACA-3' and reverse 5'-AACGCTTCACGAATTTGC GT-3'; GAPDH, forward 5'-CGGAGTCAACGGATTTGG TCGTAT-3' and reverse 5'-AGCCTTCTCCATGGTGGTGAA GAC-3'; miR-181c, forward 5'-AACATTCAACCTGTCGGT G-3' and reverse 5'-GTCGTATCCAGTGCAGGGTCCGAG GTATTCGCACTGGATACGACACTCAC-3'; miRNA universal, reverse 5'-CCAGTGCAGGGTCCGAGGTAT-3'. For normalization, GAPDH and U6 were used to normalize mRNA and miRNA, respectively. Cycles were as follows: $95^{\circ} \mathrm{C}$ for $10 \mathrm{~min}$, followed by 40 cycles at $95^{\circ} \mathrm{C}$ for $10 \mathrm{sec}$ and annealing/extension at $60^{\circ} \mathrm{C}$ for $30 \mathrm{sec}$. Each experiment was repeated at least three times, and the results were calculated according to the $2^{-\Delta \Delta \mathrm{Cq}}$ method (31).

Statistical analysis. Statistical analysis was performed with SPSS version 11.0 software (SPSS, Inc., Chicago, IL, USA). Each experiment was repeated three times. Student's t-test was used to assess the statistical significance of differences between groups. Data are presented as the mean \pm standard error of the mean. $\mathrm{P}<0.05$ was considered to indicate a statistically significant difference.

\section{Results}

${ }^{125}$ I irradiation inhibits viability and invasiveness of gastric cancer cells. To investigate the effects of ${ }^{125} \mathrm{I}$ irradiation on the viability of gastric cancer cells, KATO-III and MKN45 cells were treated with continuous ${ }^{125} \mathrm{I}$ irradiation at a dose between
0 and 8 Gy. Subsequently, MTT assay was performed to determine the effects of ${ }^{125} \mathrm{I}$ treatment. MTT assays indicated that ${ }^{125}$ I treatment significantly decreased the viability of KATO-III and MKN45 cells at a low dose $(\mathrm{P}<0.05$; Fig. $1 \mathrm{~A})$. On the basis of these results, $4 \mathrm{~Gy}$ was used for subsequent experiments.

To investigate the effects of ${ }^{125} \mathrm{I}$ irradiation on the invasion of gastric cancers, KATO-III and MKN45 cells were treated with ${ }^{125} \mathrm{I}$ irradiation at 0 (control) or $4 \mathrm{~Gy}$. In total $\sim 48 \mathrm{~h}$ later, the invasive ability of the cells was analyzed using Transwell assays. As shown in Fig. 1B, the number of KATO-III cells invading through the Matrigel following ${ }^{125} \mathrm{I}$ irradiation was clearly attenuated by $53 \%$ compared with the control group. A similar reduction in cell invasive activity was observed in MKN45 cells treated with ${ }^{125} \mathrm{I}$ irradiation $(\mathrm{P}=0.043$; Fig. $1 \mathrm{C})$. These data indicate a negative regulatory effect of ${ }^{125} \mathrm{I}$ irradiation on the viability and invasiveness of gastric cancer cells.

${ }^{125}$ I irradiation modulates $\mathrm{miR}-181 \mathrm{c}$ activity by inducing DNA demethylation at its promoter region. Previous evidence has demonstrated that ${ }^{125} \mathrm{I}$ irradiation alters the expression of DNMT1, leading to epigenetic alterations, which reactivates silenced tumor suppressor genes (11). miR-181c is a potential tumor suppressor that is epigenetically silenced by promoter hypermethylation in gastric cancers (12). Thus, the present study hypothesizes that ${ }^{125} \mathrm{I}$ irradiation may modulate the activity of the miR-181c gene by affecting its methylation status.

To confirm this hypothesis, the present study primarily examined the effects of ${ }^{125} \mathrm{I}$ irradiation on the expression of DNMT1 protein in KATO-III and MKN45 cells. DNMT1 and GAPDH proteins were detected by western blotting, and protein expression levels of DNMT1 were calculated by normalization to GAPDH density. As indicated in Fig. 2A, ${ }^{125} \mathrm{I}$ treatment lead to a significant reduction of DNMT1 protein expression in KATO-III $(\mathrm{P}=0.040)$ and MKN45 cells 

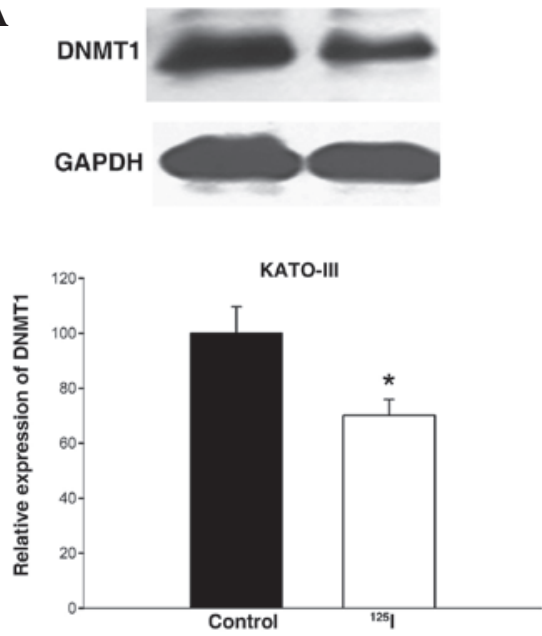

B

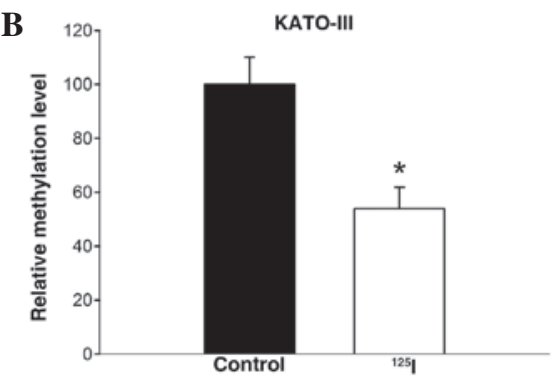

C

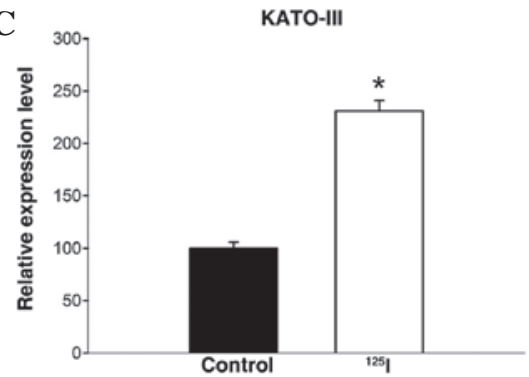

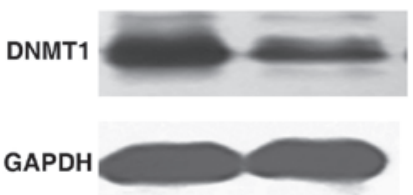
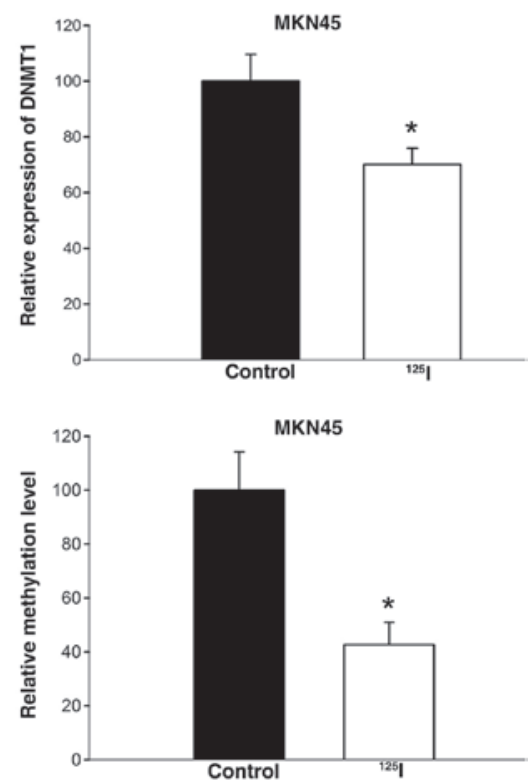

MKN45

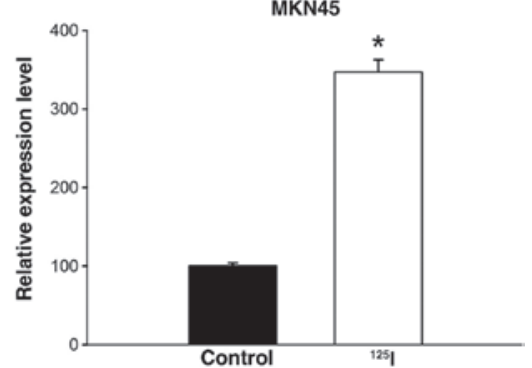

Figure 2. ${ }^{125}$ I irradiation reactivates miR-181c expression by inducing its promoter demethylation. (A) Protein levels of DNMT1 (180 kDa) and its quantification analysis by GAPDH (37 kDa) in human gastric cancer KATO-III and MKN4 cells was investigated by western blotting. (B) Effects of ${ }^{125}$ I irradiation on promoter methylation of the DNMT1 gene in KATO-III and MKN4 cells was assayed by methylated DNA immunoprecipitation-PCR. (C) Relative expression of miR-181c was detected using reverse transcription-quantitative PCR. Data are presented as the mean \pm standard error of the mean ( $=3$ ). ${ }^{*}<0.05$ vs. 0 Gy treated cells. ${ }^{125}$ I, iodine-125; miR, microRNA; DNMT1, DNA (cytosine-5)-methyltransferase 1; GAPDH, glyceraldehyde 3-phosphate dehydrogenase; PCR, polymerase chain reaction.

$(\mathrm{P}=0.025)$. This decrease of DNMT1, which is responsible for the maintenance of DNA methylation patterns, may result in methylation alterations of target genes.

To determine whether ${ }^{125} \mathrm{I}$ irradiation affects the methylation status of the miR-181c gene, a MeDIP-PCR assay was performed in gastric cancer cells treated with and without ${ }^{125} \mathrm{I}$ irradiation (4 Gy). As indicated in Fig. 2B, ${ }^{125}$ I-irradiated cells exhibited a significantly decrease in the methylation status of miR-181c compared with control cells (KATO-III, $\mathrm{P}=0.032$; MKN45, $\mathrm{P}=0.025)$; there was a $53.9 \%$ and $42.7 \%$ decrease in KATO-III and MKN45 cells, respectively. These results demonstrate that ${ }^{125}$ I irradiation induces DNA demethylation at the promoter region of the miR-181c gene.

Finally, alterations in the expression of miR-181c in gastric cancer cells following ${ }^{125} \mathrm{I}$ treatment were determined using qPCR. As indicated in Fig. 2C, ${ }^{125}$ I treatment caused upregulation of miR-181c expression in KATO-III and MKN45 cells, which was significant compared with the control group $(\mathrm{P}=0.018$ and $\mathrm{P}=0.014$, respectively). Overall, these data suggest that ${ }^{125} \mathrm{I}$ irradiation upregulates miR-181c expression in gastric cancer cells, which may be partially attributed to the irradiation inducing DNA demethylation.

miR-181c exerts a functional role as a tumor suppressor in gastric cancer cells. A previous study reported that there was a decreased expression of miR-181c in gastric cancer, and revealed that miR-181c suppresses cell growth in KATO-III and MKN45 cells (20). To further determine the functional role of miR-181c in gastric cancer cells, the invasiveness of KATO-III and MKN45 cells transfected with miR-181c mimics and scrambled negative control was evaluated by the present study.

The results of a qPCR revealed that miR-181c mimics significantly increased miR-181c expression in KATO-III 
A

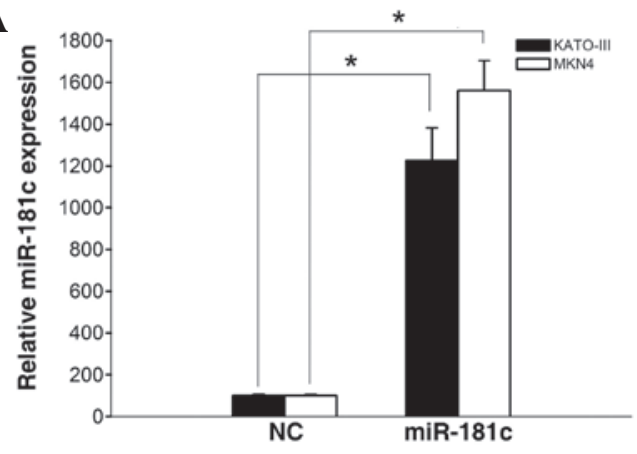

B

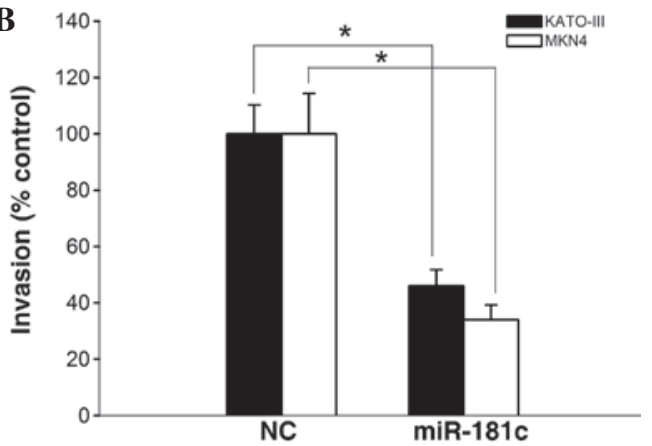

Figure 3. Effects of miR-181c on the invasiveness of gastric cancer cells. (A) Human gastric cancer KATO-III and MKN4 cells were transfected with miR-181c mimics and NC. The corresponding transfection efficiencies were detected by quantitative polymerase chain reaction. (B) Effects of miR-181c overexpression on the invasiveness of KATO-III and MKN4 cells was evaluated by Transwell assay. Data are presented as the mean \pm standard error of the mean ( $\mathrm{n}=3$ ) and normalized to the NC group, which had a value of $100 .{ }^{*} \mathrm{P}<0.05$ vs. NC-transfected cells. miR, microRNA; NC, scrambled negative control.
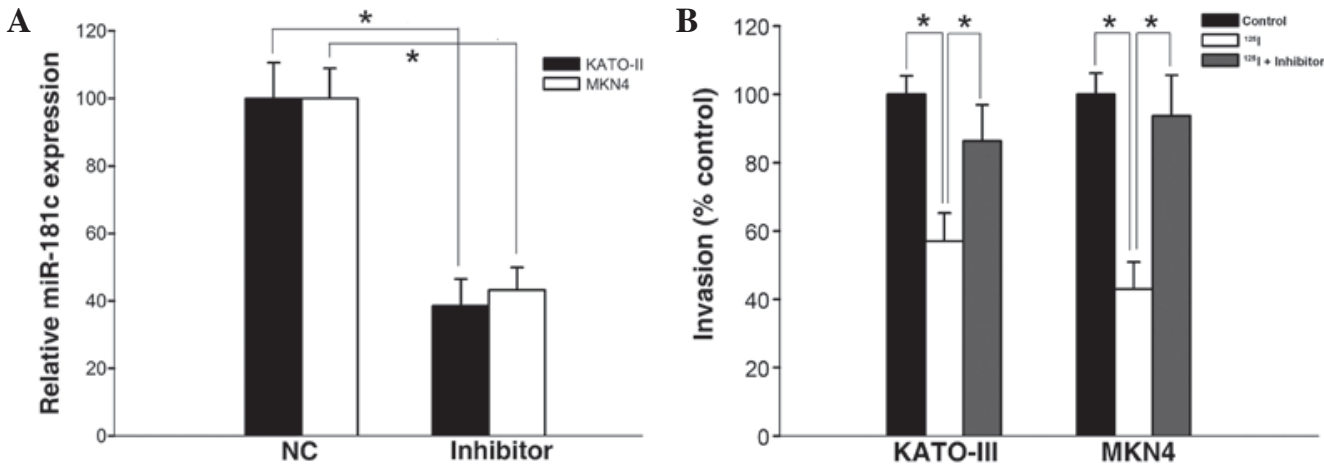

Figure 4. Inhibitory effects of ${ }^{125}$ I irradiation on cell invasiveness is compromised by miR-181c inhibitors. (A) Human gastric cancer KATO-III and MKN4 cells were transfected with miR-181c inhibitors and NC. Inhibition of miR-181c in KATO-III and MKN4 cells was verified by reverse transcription-quantitative polymerase chain reaction. (B) Transwell assays revealed that miR-181c inhibitor significantly decreased the effects of ${ }^{125} \mathrm{I}$ irradiation on the inhibition of cell invasion. Cells not irradiated with ${ }^{125} \mathrm{I}$ were included for reference. Data are presented as the mean \pm standard error of the mean ( $\mathrm{n}=3$ ) and normalized to the NC group, which had a value of $100 .{ }^{*} \mathrm{P}<0.05$ vs. NC-transfected cells. ${ }^{125} \mathrm{I}$, iodine-125; miR, microRNA; NC, scrambled negative control.

and MKN45 cells $(\mathrm{P}=0.016$ and $\mathrm{P}=0.009$, respectively; Fig. 3A), suggesting that miR-181c mimics were efficiently introduced into the cells and upregulated miR-181c expression. Furthermore, the number of gastric cancer cells invading through Matrigel following transfection with miR-181c mimics was remarkably attenuated compared with KATO-III and MKN45 cells transfected with scrambled negative control $(\mathrm{P}=0.027$ and $\mathrm{P}=0.021$, respectively; Fig. $3 \mathrm{~B})$. These data indicate a potential negative regulatory effect of miR-181c on the invasion of gastric cancer cells.

Downregulation of miR-181c compromises the anticancer effects of ${ }^{125}$ I irradiation. To evaluate the role of miR-181c on the inhibitory effect of ${ }^{125}$ I irradiation, KATO-III and MKN45 cells were treated with 4 Gy ${ }^{125}$ I irradiation followed by transfection with miR-181c inhibitors. As shown in Fig. 4A, miR-181c inhibitors significantly decreased the expression of miR-181c in KATO-III and MKN45 cells compared with the scrambled normal control-transfected cells $(\mathrm{P}=0.037$ and $\mathrm{P}=0.030$, respectively). In addition, the ${ }^{125} \mathrm{I}$-irradiation-induced inhibition on cell invasion was significantly attenuated in KATO-III and MKN45 cells transfected with the miR-181c inhibitor $(\mathrm{P}<0.05$; Fig. 4B). These data implied that miR-181c was responsible for the suppression of cell invasion, which was induced by ${ }^{125} \mathrm{I}$ irradiation.

\section{Discussion}

${ }^{125}$ I seed implantation has been widely used to treat various types of cancer, including gastric cancer, due to its high precision, low trauma to patients, strong lethality and few side effects $(9,10)$. Although ${ }^{125}$ I seed implantation has been successfully used in clinics, its radiobiological effects and underlying molecular mechanisms are not fully elucidated.

Several studies have indicated that ${ }^{125} \mathrm{I}$ seed irradiation is effective in inducing cell apoptosis in pancreatic and colonic cancer cells $(4,11,32)$. More recently, Tian et al (28) revealed that ${ }^{125} \mathrm{I}$ seeds effectively inhibit cell growth and invasion of nasopharyngeal carcinoma. However, the effects of ${ }^{125} \mathrm{I}$ seed irradiation in gastric cancer cell lines have not yet been investigated. The present study evaluated the efficacy of ${ }^{125} \mathrm{I}$ irradiation on the death of KATO-III and MKN45 cells, as assessed by cell viability assays, and demonstrated that a low dose of ${ }^{125} \mathrm{I}$ irradiation (4 Gy) effectively kills gastric cancer cells.

Previous studies have revealed that altered DNA methylation patterns may be critical in tumor inhibition resulting from consecutive low-energy ${ }^{125} \mathrm{I}$ irradiation (11). Ma et al (11) demonstrated that low-dose (4 Gy) ${ }^{125}$ I irradiation causes a significant decrease in DNMT expression in pancreatic cancer cells. Consistent with the present study, a significant 
decrease in DNMT1 expression was observed in gastric cancer xenografts implanted with ${ }^{125}$ I seeds (3). In addition, there is a clear and positive association between DNA methylation and expression of DNMTs, since DNMTs maintain DNA methylation patterns (11). As the result of decreased DNMT expression induced by ${ }^{125} \mathrm{I}$ seed irradiation, tumor suppressor genes, including BCL2/adenovirus E1B 19kDa interacting protein 3, Wnt family member $9 \mathrm{~A}$ and germ cell associated 2, are extensively reactivated by promoter demethylation (3).

miRs are known as a class of small noncoding RNAs, which are critical in cancer progression as oncogenes and tumor suppressor genes. It has been reported that numerous tumor suppressor miRs, including miR-9, miR-124 and miR-200 family, are epigenetically silenced by DNA methylation in cancer (33-35). It is reasonable to hypothesize that these miRs may be reactivated by ${ }^{125} \mathrm{I}$-irradiation inducing promoter demethylation, thereby contributing to anticancer effects. Among these tumor suppressor miRs, miR-181c has been reported to be epigenetically silenced in gastric carcinogenesis (20). In the present study, MeDIP-PCR assays were performed to examine the methylation status at the promoter region of miR-181c. As expected, the present results revealed that ${ }^{125}$ I irradiation significantly induced DNA demethylation at the promoter of the miR-181c gene in KATO-III and MKN45 cells. Additionally, a notable upregulation of miR-181c in gastric cancer cells was observed following continuous low-dose ${ }^{125} \mathrm{I}$ irradiation. These data suggested that ${ }^{125} \mathrm{I}$ irradiation induces DNA demethylation at the promoter region of miR-181c, resulting in the reactivation of miR-181c. Further experiments by the present study demonstrated that overexpression of miR-181c effectively decreased cell invasiveness. In addition, downregulation of miR-181c compromised the anticancer effects observed with ${ }^{125} \mathrm{I}$ irradiation. According to these results, it may be concluded that miR-181c is reactivated by ${ }^{125} \mathrm{I}$ irradiation through DNA demethylation, and thus, is involved in ${ }^{125} \mathrm{I}$-irradiation induced tumor inhibition.

In summary, the present study provides, to the best of our knowledge, the first demonstration that miRs are involved in the therapeutic effect of ${ }^{125}$ I seed irradiation. The present study provides an illustrative example in gastric cancer with the reactivation of miR-181c by ${ }^{125} \mathrm{I}$ irradiation, as well as its functional consequences for tumor inhibition. In addition, the present study has revealed that miR-181c reactivation may be mediated through ${ }^{125}$ I-induced demethylation, emphasizing the critical role of epigenetic regulation underlying the anticancer effects of ${ }^{125} \mathrm{I}$ irradiation.

\section{Acknowledgements}

The present study was supported by the Foundation of Applied Basic Research Program of Yunnan Province (Kunming, China; grant nos. 2011FB150 and 2013FB183).

\section{References}

1. Wang Z, Wang J, Yang Y, Hao B, Wang R, Li Y and Wu Q: Loss of has-miR-337-3p expression is associated with lymph node metastasis of human gastric cancer. J Exp Clin Cancer Res 32: 76, 2013.

2. Chu D, Zhu S, Li J, Ji G, Wang W, Wu G and Zheng J: CD147 expression in human gastric cancer is associated with tumor recurrence and prognosis. PloS One 9: e101027, 2014.
3. Ma ZH, Yang Y, Zou L and Luo KY: 125I seed irradiation induces up-regulation of the genes associated with apoptosis and cell cycle arrest and inhibits growth of gastric cancer xenografts. J Exp Clin Cancer Res 31: 61, 2012.

4. Zhuang HQ, Wang JJ, Liao AY, Wang JD and Zhao Y: The biological effect of 125 I seed continuous low dose rate irradiation in CL187 cells. J Exp Clin Cancer Res 28: 12, 2009.

5. Yu Y, Anderson LL, Li Z, Mellenberg DE, Nath R, Schell MC, Waterman FM, Wu A and Blasko JC: Permanent prostate seed implant brachytherapy: Report of the american association of physicists in medicine task group No. 64. Med Phys 26: 2054-2076, 1999.

6. Wang JJ, Yuan HS, Li JN, Jiang WJ, Jiang YL and Tian SQ: Interstitial permanent implantation of 125I seeds as salvage therapy for re-recurrent rectal carcinoma. Int J Colorectal Dis 24: 391-399, 2009.

7. Zhao E, Xiao S, Qin Y, Wang Q, Guo M and Wang R: Permanent interstitial implantation of 125I seeds for 5 cases of advanced head and neck cancer. Lin Chuang Er Bi Yan Hou Ke Za Zhi 18: 348-349 352, 2004.

8. Wang ZM, Wu J, Wang GC, Ren JL and Kjelle D: Efficacy of permanent interstitial implantation of $125 \mathrm{I}$ seeds for solitary brain metastasis from non-small cell lung carcinoma. Ai Zheng 21: 1145-1148, 2002.

9. Wang J, Sui A, Jia Y, Xu B, Wei L, Chen J and Shen W: Treatment of unresectable advanced gastric cancer using lodine-125 brachytherapy. Chinese Journal of Clinical Oncology 3: 212-215, 2006.

10. Joyce F, Burcharth F, Holm HH and Strøyer I: Ultrasonically guided percutaneous implantation of iodine-125 seeds in pancreatic carcinoma. Int J Radiat Oncol Biol Phys 19: 1049-1052, 1990.

11. Ma JX, Jin ZD, Si PR, Liu Y, Lu Z, Wu HY, Pan X, Wang LW, Gong YF, Gao J and Zhao-shen L: Continuous and low-energy 125I seed irradiation changes DNA methyltransferases expression patterns and inhibits pancreatic cancer tumor growth. J Exp Clin Cancer Res 30: 35, 2011.

12. Suzuki H, Maruyama R, Yamamoto E and Kai M: DNA methylation and microRNA dysregulation in cancer. Mol Oncol 6: 567-578, 2012.

13. Zhang B, Pan X, Cobb GP and Anderson TA: microRNAs as oncogenes and tumor suppressors. Dev Biol 302: 1-12, 2007.

14. Yu S, Lu Z, Liu C, Meng Y, Ma Y, Zhao W, Liu J, Yu J and Chen J: miRNA-96 suppresses KRAS and functions as a tumor suppressor gene in pancreatic cancer. Cancer Res 70: 6015-6025, 2010.

15. Lopez-Serra P and Esteller M: DNA methylation-associated silencing of tumor-suppressor microRNAs in cancer. Oncogene 31: 1609-1622, 2012.

16. Lee YS and Dutta A: The tumor suppressor microRNA let-7 represses the HMGA2 oncogene. Genes Dev 21: 1025-1030, 2007.

17. Noguchi S, Mori T, Hoshino Y, Maruo K, Yamada N, Kitade Y, Naoe T and Akao Y: MicroRNA-143 functions as a tumor suppressor in human bladder cancer T24 cells. Cancer Lett 307: 211-220, 2011.

18. Nan Y, Han L, Zhang A, Wang G, Jia Z, Yang Y, Yue X, Pu P, Zhong $\mathrm{Y}$ and Kang C: MiRNA-451 plays a role as tumor suppressor in human glioma cells. Brain Res 1359: 14-21, 2010.

19. Saito Y, Suzuki H, Tsugawa H, Nakagawa I, Matsuzaki J, Kanai Y and Hibi T: Chromatin remodeling at Alu repeats by epigenetic treatment activates silenced microRNA-512-5p with downregulation of Mcl-1 in human gastric cancer cells. Oncogene 28: 2738-2744, 2009

20. Hashimoto Y, Akiyama Y, Otsubo T, Shimada S and Yuasa Y: Involvement of epigenetically silenced microRNA-181c in gastric carcinogenesis. Carcinogenesis 31: 777-784, 2010.

21. Zhang Y, Yan LX, Wu QN, Du ZM, Chen J, Liao DZ, Huang MY, Hou JH, Wu QL, Zeng MS, et al: miR-125b is methylated and functions as a tumor suppressor by regulating the ETS1 proto-oncogene in human invasive breast cancer. Cancer Res 71: 3552-3562, 2011.

22. Ng EK, Tsang WP, Ng SS, Jin HC, Yu J, Li JJ, Röcken C, Ebert MP, Kwok TT and Sung JJ: MicroRNA-143 targets DNA methyltransferases 3A in colorectal cancer. Br J Cancer 101: 699-706, 2009.

23. Tsai KW, Liao YL, Wu CW, Hu LY, Li SC, Chan WC, Ho MR, Lai CH, Kao HW, Fang WL, et al: Aberrant hypermethylation of miR-9 genes in gastric cancer. Epigenetics 6: 1189-1197, 2011. 
24. Tsai KW, Wu CW, Hu LY, Li SC, Liao YL, Lai CH, Kao HW, Fang WL, Huang KH, Chan WC and Lin WC: Epigenetic regulation of miR-34b and miR-129 expression in gastric cancer. Int J Cancer 129: 2600-2610, 2011.

25. Tsuruta T, Kozaki K, Uesugi A, Furuta M, Hirasawa A, Imoto I, Susumu N, Aoki D and Inazawa J: miR-152 is a tumor suppressor microRNA that is silenced by DNA hypermethylation in endometrial cancer. Cancer Res 71: 6450-6462, 2011.

26. Vogt M, Munding J, Grüner M, Liffers ST, Verdoodt B, Hauk J, Steinstraesser L, Tannapfel A and Hermeking H: Frequent concomitant inactivation of $\mathrm{miR}-34 \mathrm{a}$ and $\mathrm{miR}-34 \mathrm{~b} / \mathrm{c}$ by $\mathrm{CpG}$ methylation in colorectal, pancreatic, mammary, ovarian, urothelial and renal cell carcinomas and soft tissue sarcomas. Virchows Archiv 458: 313-322, 2011.

27. Vrba L, Jensen TJ, Garbe JC, Heimark RL, Cress AE, Dickinson S, Stampfer MR, Futscher BW: Role for DNA methylation in the regulation of miR-200c and miR-141 expression in normal and cancer cells. PloS One 5: e8697, 2010.

28. Tian Y, Xie Q, Tian Y, Liu Y, Huang Z, Fan C, Hou B, Sun D, Yao K and Chen T: Radioactive ${ }^{125} \mathrm{I}$ seed inhibits the cell growth, migration and invasion of nasopharyngeal carcinoma by triggering DNA damage and inactivating VEGF-A/ERK signaling. PloS One 8: e74038, 2013.

29. Yang TS, Yang XH, Wang XD, Wang YL, Zhou B and Song ZS: MiR-214 regulate gastric cancer cell proliferation, migration and invasion by targeting PTEN. Cancer Cell Int 13: 68, 2013.
30. Clark C, Palta P, Joyce CJ, Scott C, Grundberg E, Deloukas P, Palotie A and Coffey AJ: A comparison of the whole genome approach of MeDIP-seq to the targeted approach of the Infinium HumanMethylation450 BeadChip $\left({ }^{\circledR}\right)$ for methylome profiling. PLoS One 7: e50233, 2012.

31. Livak KJ and Schmittgen TD: Analysis of relative gene expression data using real-time quantitative PCR and the 2(-Delta Delta C(T)) Method. Methods 25: 402-408, 2001.

32. Ma Z, Yang Y, Yang G, Wan J, Li G, Lu P and Du L: Iodine-125 induces apoptosis via regulating p53, microvessel density, and vascular endothelial growth factor in colorectal cancer. World J Surg Oncol 12: 222, 2014.

33. Wilting SM, van Boerdonk RA, Henken FE, Meijer CJ, DiosdadoB, Meijer GA, le Sage C, Agami R, Snijders PJ and Steenbergen RD: Methylation-mediated silencing and tumour suppressive function of hsa-miR-124 in cervical cancer. Mol Cancer 9: 167, 2010.

34. Wiklund ED, Bramsen JB, Hulf T, Dyrskjøt L, Ramanathan R, Hansen TB, Villadsen SB, Gao S, Ostenfeld MS, Borre M, et al: Coordinated epigenetic repression of the miR-200 family and miR-205 in invasive bladder cancer. Int J Cancer 128: 1327-1334, 2011.

35. Neves R, Scheel C, Weinhold S, Honisch E, Iwaniuk KM, Trompeter HI, Niederacher D, Wernet P, Santourlidis S and Uhrberg M: Role of DNA methylation in miR-200c/141 cluster silencing in invasive breast cancer cells. BMC Res Note 3: 219, 2010. 